\title{
Earthquake Cycle Deformation in the Tibetan Plateau with a Weak Mid-Crustal Layer
}

\section{Citation}

DeVries, Phoebe M. R., and Brendan J. Meade. 2013. “Earthquake Cycle Deformation in the Tibetan Plateau with a Weak Mid-Crustal Layer." Journal of Geophysical Research: Solid Earth 118 (6) (June): 3101-3111. doi:10.1002/jgrb.50209. http://dx.doi.org/10.1002/jgrb.50209.

\section{Published Version}

doi:10.1002/jgrb.50209

\section{Permanent link}

http://nrs.harvard.edu/urn-3:HUL.InstRepos:12497939

\section{Terms of Use}

This article was downloaded from Harvard University's DASH repository, and is made available under the terms and conditions applicable to Other Posted Material, as set forth at http:// nrs.harvard.edu/urn-3:HUL.InstRepos:dash.current.terms-of-use\#LAA

\section{Share Your Story}

The Harvard community has made this article openly available.

Please share how this access benefits you. Submit a story.

\section{Accessibility}




\title{
Earthquake cycle deformation in the Tibetan plateau with a weak mid-crustal layer
}

\author{
Phoebe M. R. DeVries ${ }^{1}$ and Brendan J. Meade ${ }^{1}$ \\ Received 15 August 2012; revised 26 April 2013; accepted 1 May 2013.
}

[1] Geodetic observations of interseismic deformation across the Tibetan plateau contain information about both tectonic and earthquake cycle processes. Time-variations in surface velocities between large earthquakes are sensitive to the rheological structure of the subseismogenic crust, and, in particular, the viscosity of the middle and lower crust. Here we develop a semianalytic solution for time-dependent interseismic velocities resulting from viscoelastic stress relaxation in a localized midcrustal layer in response to forcing by a sequence of periodic earthquakes. Earthquake cycle models with a weak midcrustal layer exhibit substantially more near-fault preseismic strain localization than do classic two-layer models at short $(<100 \mathrm{yr})$ Maxwell times. We apply both this three-layer model and the classic two-layer model to geodetic observations before and after the $1997 M_{W}=7.6$ Manyi and $2001 M_{W}=7.8$ Kokoxili strike-slip earthquakes in Tibet to estimate the viscosity of the crust below a $20 \mathrm{~km}$ thick seismogenic layer. For these events, interseismic stress relaxation in a weak (viscosity $\leq 10^{18.5} \mathrm{~Pa} \cdot \mathrm{s}$ ) and thin (height $\leq 20 \mathrm{~km}$ ) midcrustal layer explains observations of both preseismic near-fault strain localization and rapid $(>50 \mathrm{~mm} / \mathrm{yr})$ postseismic velocities in the years following the coseismic ruptures. We suggest that earthquake cycle models with a localized midcrustal layer can simultaneously explain both preseismic and postseismic geodetic observations with a single Maxwell viscosity, while the classic two-layer model requires a rheology with multiple relaxation time scales.

Citation: DeVries, P. M. R., and B. J. Meade (2013), Earthquake cycle deformation in the Tibetan plateau with a weak mid-crustal layer, J. Geophys. Res. Solid Earth, 118, doi:10.1002/jgrb.50209.

\section{Introduction}

[2] Geodetic observations of surface velocities from both early and late in the earthquake cycle may provide constraints on the rheology of the subseismogenic crust and mantle. Within the Tibetan plateau, transient postseismic deformation rates up to $\sim 100 \mathrm{~mm} / \mathrm{yr}$ have been observed following the $1997 M_{W}=7.6$ Manyi [Ryder et al., 2007] and 2001 $M_{W}=7.8$ Kokoxili earthquakes (Figure 1) [ChaoJun et al., 2009; Diao et al., 2011; Ryder et al., 2011]. These observations of time-dependent postseismic surface deformation have been explained with earthquake cycle models that relate transient surface velocities to the viscous relaxation of stresses at depth [Ryder et al., 2007, 2011]. In these viscoelastic models, stresses generated during the coseismic stage of the earthquake cycle are relaxed through viscoelastic processes at depth to produce time-dependent surface velocities throughout the interseismic period of the earthquake cycle.

Additional supporting information may be found in the online version of this article.

${ }^{1}$ Department of Earth and Planetary Sciences, Harvard University, Cambridge, Massachusetts, USA.

Corresponding author: P. M. R. DeVries, Department of Earth and Planetary Sciences, Harvard University, 20 Oxford St., Cambridge, MA 02138, USA. (phoeberobinson@fas.harvard.edu)

(C)2013. American Geophysical Union. All Rights Reserved 2169-9313/13/10.1002/jgrb.50209
Rapid postseismic deformation observed in the months following the 1997 Manyi rupture can be explained by a two-layer earthquake cycle model consisting of an elastic upper crust overlying a semi-infinite standard linear solid layer with a relatively low viscosity $\left(\sim 4 \times 10^{18} \mathrm{~Pa} \cdot \mathrm{s}\right)$ subseismogenic layer beneath the Tibetan upper crust [Ryder et al., 2007]. The same postseismic deformation can also be explained by an elastic upper crust overlying a Maxwell rheology layer with viscosity decreasing exponentially with depth [Yamasaki and Houseman, 2012].

[3] In contrast, GPS observations from late in the earthquake cycle (preseismic) on the western Kunlun Fault, $\sim 500 \mathrm{~km}$ east of the Manyi earthquake (Figure 1), have been interpreted as consistent with relatively high Maxwell viscosities [Hilley et al., 2005]. Bayesian inferences of the Maxwell relaxation times suggest that higher viscosities, $\sim 10^{20} \mathrm{~Pa} \cdot \mathrm{s}$, most probably explain pre-earthquake velocity gradients near the Kunlun fault [Hilley et al., 2005]. The inference of a relatively high viscosity is based on the observation of a large interseismic GPS velocity gradient $(\sim 12 \mathrm{~mm} / \mathrm{yr})$ within $\sim 700 \mathrm{~km}$ of the Kunlun fault just prior to the $2001 M_{W}=7.8$ Kokoxili earthquake [Zhang et al., 2004]. This preseismic differential velocity is comparable to the geologically constrained long-term fault slip rate, $11.7 \pm 1.5 \mathrm{~mm} / \mathrm{yr}$ [Van der Woerd et al., 2002]. However, the twolayer Maxwell earthquake cycle model [Savage and Prescott, 1978] with a low viscosity of $\sim 10^{18} \mathrm{~Pa} \cdot \mathrm{s}$ and an earthquake recurrence interval of 300 years [Haibing et al., 


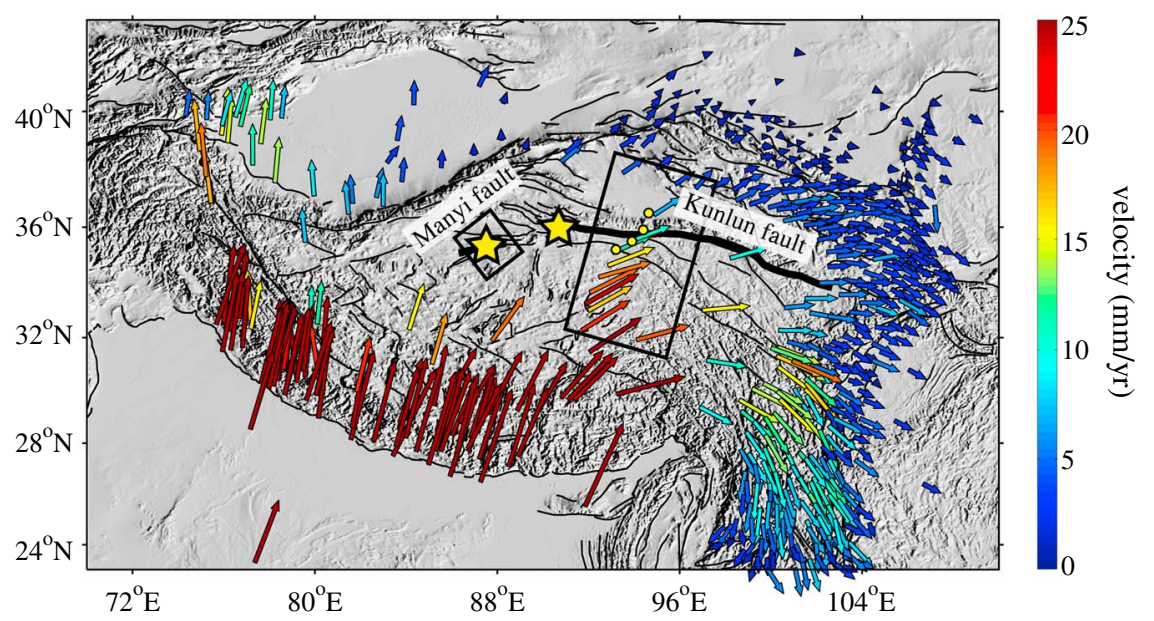

Figure 1. Interseismic GPS velocities [Zhang et al., 2004] and shaded relief map of Tibet. Velocities are shown in a nominally Asian reference frame and are color coded by magnitude with warmer colors indicating faster velocities. The yellow stars show the locations of the $1997 M_{W}=7.6$ Manyi and $2001 M_{W}=7.8$ Kokoxili earthquakes. The black box across the Manyi fault shows the approximate location of interferograms before and after the earthquake [Ryder et al., 2007; Bell et al., 2011]. The black box across the Kunlun fault shows the location of the fault-parallel velocity profile (Figure 3b). Yellow circles show the locations of the four Chinese Seismological Bureau GPS stations deployed one month after the Kokoxili earthquake [ChaoJun et al., 2009].

2005] predicts a differential velocity of only $1-5 \mathrm{~mm} / \mathrm{yr}$ late in the earthquake cycle. This discrepancy in subseismogenic viscosity estimates is notable because similar behavior was observed before and after the Manyi and Kokoxili earthquakes, with epicenters less than $500 \mathrm{~km}$ apart.

[4] The development of models that simultaneously explain preseismic and postseismic deformation is a step toward understanding the temporal evolution of deformation and stress transfer throughout the entire earthquake cycle. Several previous earthquake cycle models in Tibet have been based on the analysis of two-layer models (Figure $2 b$ ) with an elastic upper crust (schizosphere) above a homogeneous semi-infinite Maxwell rheology viscoelastic layer (plastosphere) [Hilley et al., 2005, 2009; Ryder et al., 2007; Yamasaki and Houseman, 2012]. Here, we consider a three-layer model with a Maxwell rheology midcrustal layer embedded between an

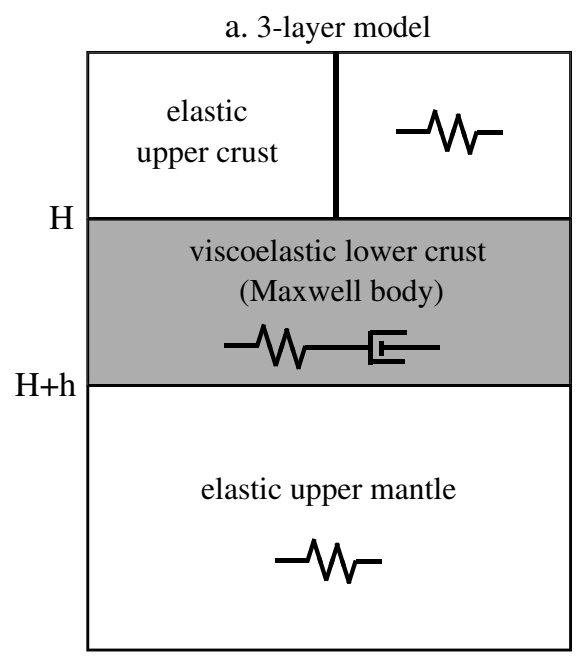

elastic upper crust and an elastic lower crust/upper mantle (Figure 2a). This three-layer model has been proposed before [Hearn, 2003; Matsu'ura et al., 1981; Ryder et al., 2007; Segall, 2010], but has never been used to explain both postseismic and preseismic observations simultaneously.

[5] This three-layer model (Figure 2a), although simple in both geometry and rheology, is motivated by three observational arguments for the presence of a relatively weak, and perhaps low viscosity, middle or lower crustal layer in the Tibetan plateau. First, quartz textures from Bhutan suggest that the Greater Himalayan Sequence is part of an extruded, and possibly low-viscosity, channel underneath the plateau [Grujic et al., 1996, 2002]. Second, both magnetotelluric and wide-angle seismic reflection data are consistent with the presence of potentially weakening fluids at $13-18 \mathrm{~km}$ depth beneath the Yadong-Gulu rift in southern Tibet

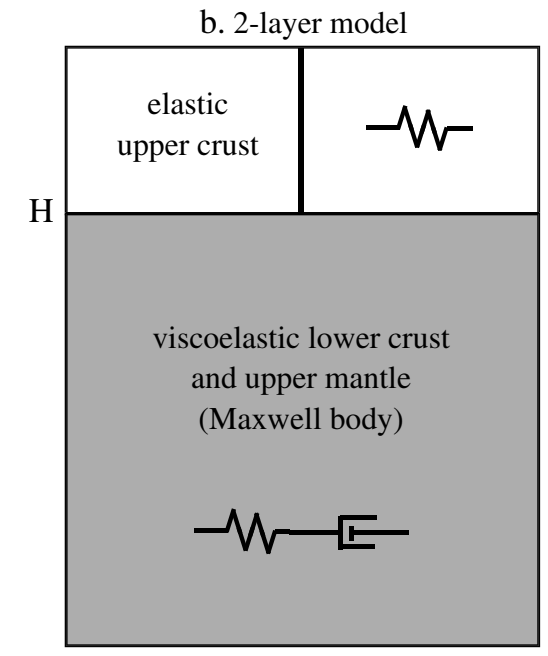

Figure 2. Schematic diagrams of the (a) three-layer and (b) two-layer model geometries. The thicknesses of the elastic upper crust and viscoelastic midcrustal layer given by $H$ and $h$, respectively. 

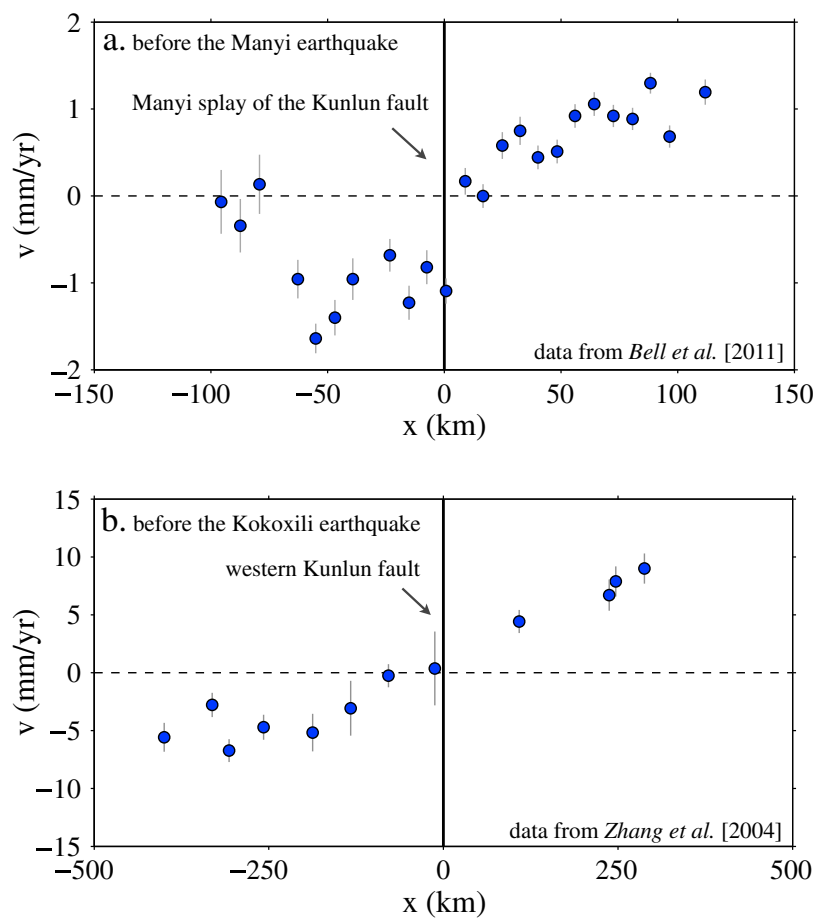

Figure 3. Preseismic fault parallel velocities. (a) Profile across the Manyi fault prior to the 1997 earthquake, showing the weighted mean of the line-of-sight velocities, converted into fault parallel velocities [Bell et al., 2011]. The blue circles are the data points and the grey lines show $1 \sigma$ uncertainties. (b) GPS velocities across the Kunlun fault before the 2001 earthquake [Zhang et al., 2004], showing a smooth velocity profile with a differential velocity of $\sim 12 \mathrm{~mm} / \mathrm{yr}$. Note the difference in the horizontal and vertical axis scales.

[Nelson et al., 1996; Makovsky et al., 1996]. Third, relatively slow seismic velocities in southeastern Tibet have also been interpreted as hot, and potentially weak, material at shallow depths [Royden et al., 2008; Yao et al., 2006, 2008]. Furthermore, numerical models designed to explain the large-scale structure and evolution of the Tibetan plateau and margins have found a key role for a ductile and weak middle to lower crust [Bird, 1991; Royden, 1996; Royden et al., 1997; Clark and Royden, 2000; Shen et al., 2001; Beaumont et al., 2001, 2004; Jamieson et al., 2004, Clark et al., 2005; Cook and Royden, 2008]. However, the inference of a weak crustal layer that may allow for the kinematic decoupling of the upper crust from the upper mantle is not uniquely supported. Shear wave splitting observations have been interpreted to suggest that the crust and mantle underneath Tibet are kinematically coupled [Holt, 2000; Flesch et al., 2005]. Similarly, vertical strength profiles of the crust and upper mantle beneath Tibet constrained by estimates of seismogenic and effective elastic thickness [Jackson, 2002; Jackson et al., 2008] have suggested that while the middle to lower crust may be weak, there is little evidence for a deeper, strong (high viscosity) layer beneath it [Jackson, 2002; Jackson et al., 2008].

[6] Here we integrate geodetic observations of both preseismic and postseismic surface deformation rates spanning the $1997 M_{W}=7.6$ Manyi and $2001 M_{W}=7.8$ Kokoxili earthquakes [Zhang et al., 2004; ChaoJun et al., 2009; Diao et al., 2011; Bell et al., 2011; Ryder et al., 2007, 2011] with a simple three-layer viscoelastic earthquake cycle model to constrain the viscosity and thickness of the midcrust beneath the Kunlun fault in Tibet. To do this, we develop a two-dimensional semianalytic solution for the time-dependent evolution of interseismic deformation in response to an infinite sequence of periodic earthquakes with viscoelastic stress relaxation confined to a midcrustal layer. We quantify the trade-offs between viscoelastic layer thickness and viscosity and assess whether or not both preseismic and postseismic deformation can be adequately explained with a single-viscosity model, or if polyviscous rheologies are required. The model developed here, and viscosities estimated, are most directly comparable to two-dimensional models of the entire earthquake cycle [e.g., Savage and Prescott, 1978; Hetland and Hager, 2005; Segall, 2002; Hilley et al., 2005; Savage, 1990, 2000; Dixon et al., 2002, 2003], rather than three-dimensional models of rapid postseismic deformation alone [e.g., Ryder et al., 2007, 2011; Hearn et al., 2009; Pollitz, 2005].

\section{Geodetic Observations of Preseismic and Postseismic Deformation in Tibet}

[7] Interferometric synthetic aperture radar (InSAR) techniques have been used to measure near-fault velocities prior to [Bell et al., 2011] and following [Ryder et al., 2007] the $1997 M_{W}=7.6$ Manyi earthquake. Preseismic InSAR data across the Manyi fault [Bell et al., 2011] reveal a differential fault-parallel velocity of $\sim 3 \mathrm{~mm} / \mathrm{yr}$ within $\sim 400 \mathrm{~km}$ of the fault trace in the 5 years leading up to the coseismic rupture. Here we consider the running mean of InSAR line-of-sight estimates (Figure 3a), converting range change estimates to fault parallel displacements using the reported satellite look angle of $23^{\circ}$, corresponding to $1 \mathrm{~mm} / \mathrm{yr}$ of horizontal motion [Bell et al., 2011]. Postseismic deformation following the Manyi earthquake measured using InSAR techniques suggests an annual average velocity of $75 \pm 19 \mathrm{~mm} / \mathrm{yr}$ at a distance of $\sim 20 \mathrm{~km}$ from the fault trace (supporting information) [Ryder et al., 2007].

[8] Interseismic GPS velocities in Tibet acquired prior to the $2001 M_{W}=7.8$ Kokoxili earthquake (Figure 1) include an array of GPS stations along the Qinghai-Tibet Highway,

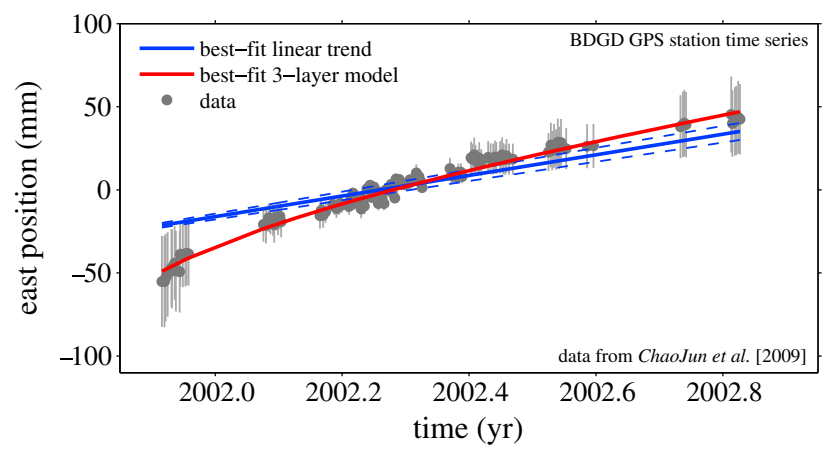

Figure 4. East-west velocity time-series from Chinese Seismological Bureau GPS station BDGD, deployed one month after the Kokoxili earthquake at a distance $30 \mathrm{~km}$ south of the Kunlun fault [ChaoJun et al., 2009]. Average velocity over this interval and $1 \sigma$ confidence bounds are shown in blue and dashed blue respectively. The best-fit three-layer model is shown in red $\left(h=2 \mathrm{~km}, \eta=10^{17.2} \mathrm{~Pa} \cdot \mathrm{s}\right)$. 


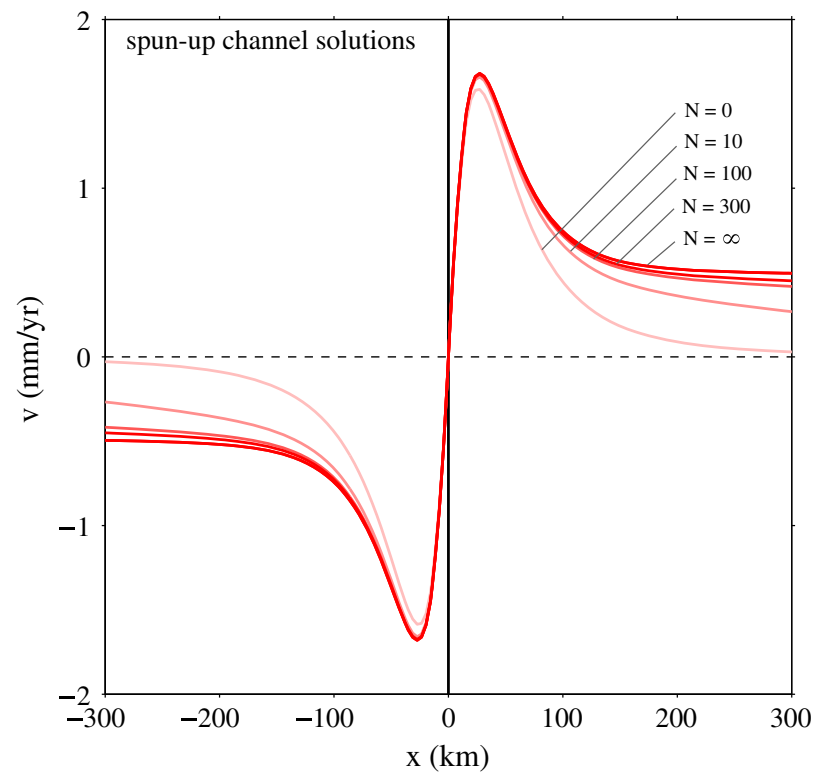

Figure 5. Fault parallel velocities (red) as a function of the number of past earthquakes $N$. As $N$ becomes large the solution approaches a spun-up or cycle invariant state. The viscosity here is assumed to be $10^{19} \mathrm{~Pa} \cdot \mathrm{s}$ with midcrustal layer thickness $h=20 \mathrm{~km}$ and the velocity profiles are shown immediately after the most recent earthquake $\left(t=0^{+}\right)$.

which crosses the central Kunlun Fault $\sim 200 \mathrm{~km}$ east of the epicenter of the 2001 Manyi event [Zhang et al., 2004]. These measurements reveal an apparently smooth preseismic velocity gradient, with a differential velocity of $\sim 12 \mathrm{~mm} / \mathrm{yr}$ within $600 \mathrm{~km}$ of the fault trace (Figure 3b). In the weeks following the coseismic rupture, four continuous GPS stations were deployed across the Qinghai-Tibet highway to record postseismic deformation [ChaoJun et al., 2009] including station BDGD at a distance of $\sim 30 \mathrm{~km}$ from the fault trace (Figure 4). At station BDGD, the average postseismic velocity from 18 to 351 days after the earthquake was $62 \pm 4 \mathrm{~mm} / \mathrm{yr}$

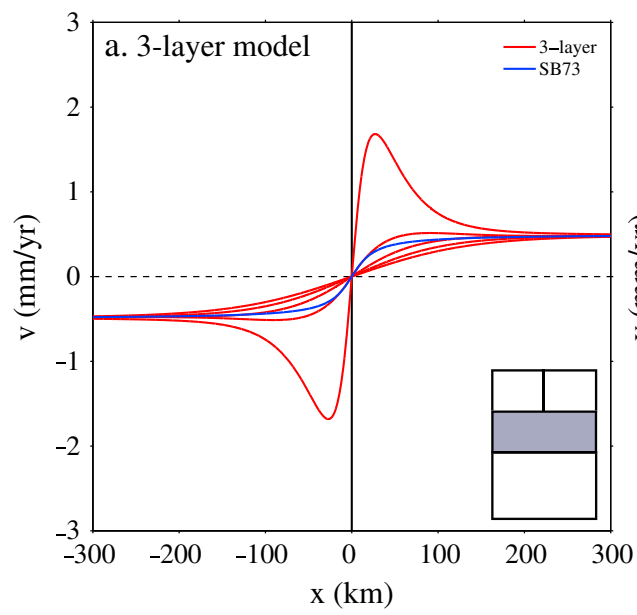

(Figure 4) [ChaoJun et al., 2009; Diao et al., 2011]. The average annual postseismic velocity is an idealization of a set of complex observations including somewhat asymmetric deformation across the Kunlun fault, which has been hypothesized to result from lateral changes in material properties in the Qaidam basin to the north [Ryder et al., 2011]. Three-dimensional variations in fault geometry could also be responsible for this asymmetric deformation, such as the changes in dip angle that have been proposed along the Manyi fault [Funning et al., 2007].

[9] Both of these earthquakes share preseismic velocity gradients that are localized within several hundred kilometers of the active fault trace. However, at distances less than $100 \mathrm{~km}$ away from the fault trace, preseismic differential velocities appear to be less than the geologically estimated long-term fault slip rate of $\sim 11 \pm 2 \mathrm{~mm} / \mathrm{yr}$ [Van der Woerd et al., 1998, 2000, 2002] in the vicinity of the Kokoxili rupture. Also common to both events is evidence for rapid near-field $(<50 \mathrm{~km}$ from fault trace) postseismic deformation at rates exceeding five times the long-term fault slip rate.

\section{Time-Dependent Viscoelastic Earthquake Cycle Models}

[10] These geodetic observations demonstrate that deformation rates between large earthquakes are not steady in time, although deformation outside of the decadal postseismic regime is often effectively approximated as such in Tibet [e.g., Bilham et al., 1997; Wallace et al., 2004; Chen et al., 2004; Meade, 2007; Burchfiel et al., 2008; Loveless and Meade, 2011]. Time-dependent deformation is typically modeled as resulting from either localized deformation on a deep shear zone extending beneath the seismogenic fault and governed either by viscous or frictional behavior [e.g., Montesi, 2004] or distributed deformation in a viscoelastic layer beneath the upper crust [e.g., Hilley et al., 2005]. Here we consider only the second of these two possibilities as it bears directly on the weak layer or channel hypothesis frequently proposed for the Tibetan plateau.

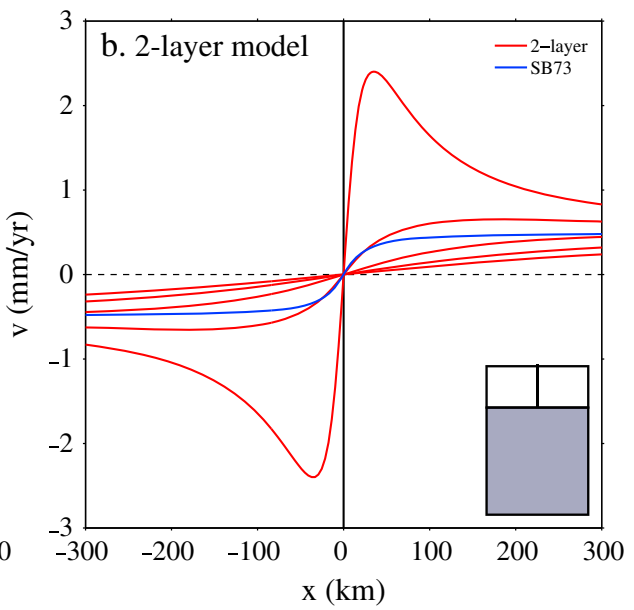

Figure 6. (a) Time-variable fault-parallel velocity profile for the three-layer model with an $H=20 \mathrm{~km}$ thick upper crust and an $h=20 \mathrm{~km}$ viscoelastic lower crust with a viscosity of $10^{19} \mathrm{~Pa} \cdot \mathrm{s}$. (b) Time-variable faultparallel velocity profiles for the two-layer model with a $20 \mathrm{~km}$ thick upper crust and a viscosity of $10^{19} \mathrm{~Pa} \cdot \mathrm{s}$ in the viscoelastic plastosphere. Time-independent interseismic velocity profiles from the steady elastic half-space model [Savage and Burford, 1973] are shown in blue for reference. 

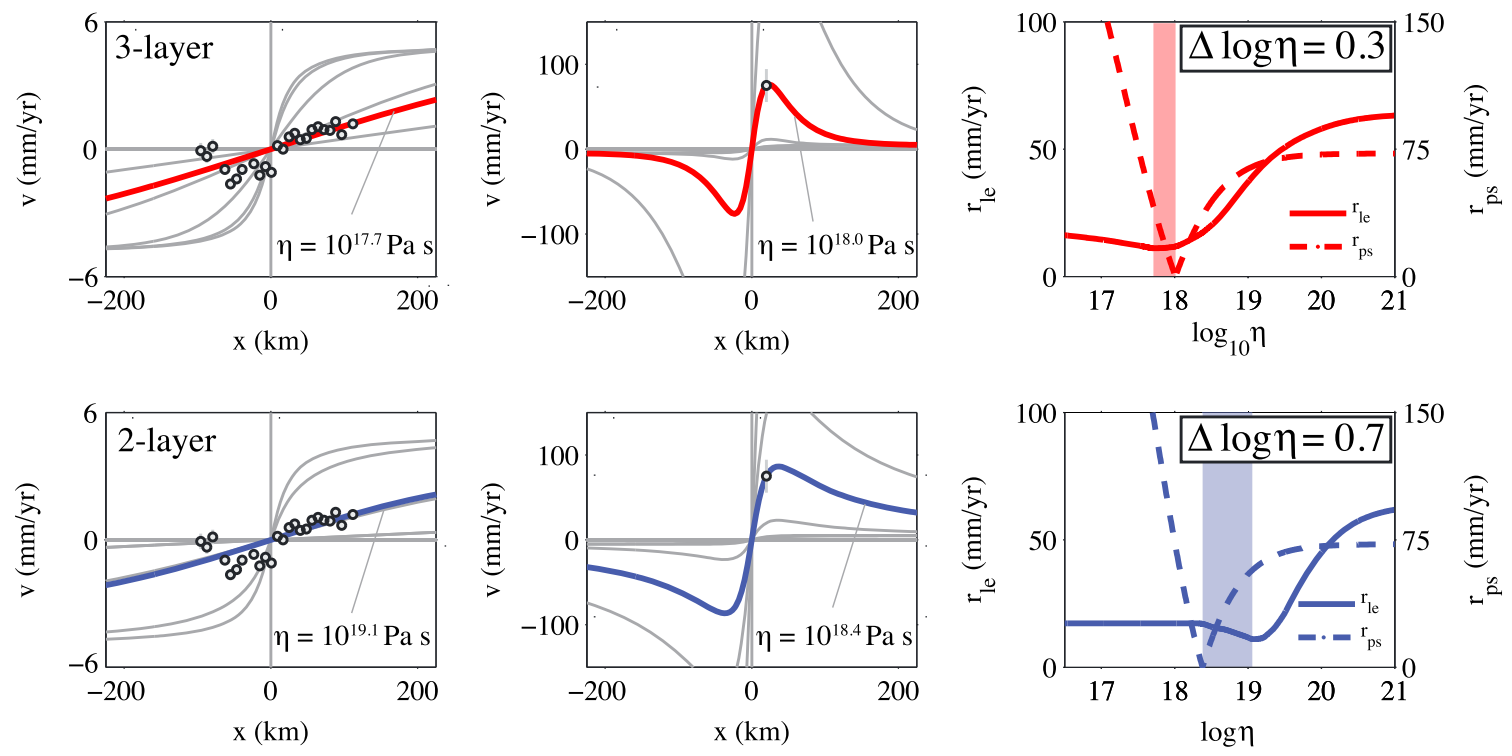

Figure 7. Best-fitting models and observations from before and after the Manyi earthquake for the threelayer model (red) and the two-layer model (blue). The first row shows the results for three-layer models with middle crust thickness of $h=10 \mathrm{~km}$, and the second row shows the results of the two-layer model. The first column shows the data from before the earthquake (grey circles) [Bell et al., 2011], and the best-fitting late-in-the-earthquake cycle velocity profile from each model. Gray curves show the predicted velocity profiles for viscosities of $\left(10^{17}, 10^{18}, 10^{19}, 10^{20}, 10^{21}\right) \mathrm{Pa} \cdot \mathrm{s}$. The second column shows the observed postseismic velocity (grey circle) [Ryder et al., 2007] and the best-fitting postseismic velocity profile from each model; again, grey curves show the predicted velocity profiles for the same range of viscosities as above. The third column shows the model residuals for the data before the Manyi earthquake (solid lines) as a function of viscosity, and the model residuals for the postseismic data (dotted lines). Minima of the two residuals curves are close together, $|\Delta \log \eta|=0.3$, for the three-layer models, demonstrating that the three-layer model can explain the entire earthquake cycle with a single viscosity. By contrast, the minima of the two curves for the two-layer model are much farther apart, $|\Delta \log \eta|=0.7$.

[11] To calculate the time-dependent velocities throughout the earthquake cycle for the three-layer model (Figure 2a), we extend previous work on representative models of vertical, infinitely long, two-dimensional, strike-slip faults. We restrict our study to two-dimensional models to facilitate comparison with these previous studies [e.g., Savage and Prescott, 1978; Hetland and Hager, 2005; Segall, 2002; Hilley et al., 2005; Savage, 1990, 2000; Dixon et al., 2002, 2003].

[12] In classic two-layer models (Figure 2b), the upper crust (schizosphere) is assumed to behave elastically and the lower crust and upper mantle beneath are modeled as a homogeneous half-space with a Maxwell viscoelastic rheology (plastosphere) [Nur and Mavko, 1974; Savage and Prescott, 1978]. The time-dependent solution for surface velocities in response to a single earthquake in a two-layer elastic model can either be obtained analytically using the method of images [e.g., Savage and Prescott, 1978; Savage, 2000] or semianalytically with propagator matrices [Ward, 1985]. With both methods, the correspondence principle is applied to transform the quasi-static viscoelastic problem into an equivalent elastic problem with a timedependent shear modulus in the Laplace domain [e.g., Nur and Mavko, 1974; Savage and Prescott, 1978; Hetland and Hager, 2005]. For the three-layer model, in which a Maxwell viscoelastic midcrustal layer is sandwiched between an elastic upper crust and an elastic upper mantle [Ryder et al., 2007; Segall, 2010] (Figure 2a), we use the propagator matrix method [e.g., Ward, 1985; Segall, 2010] to calculate the stresses and displacements due to a dislocation while requiring stress continuity at layer interfaces [Gilbert and Backus, 1966]. Following Segall [2010], we find the solution for the response to a single earthquake in the Fourier domain for the viscoelastic three-layer model, $v_{1}$ (Appendix A).

[13] Due to the fact that the Kunlun fault has accumulated tens of kilometers of offset over the last $\sim 15 \mathrm{Ma}[F u$ and Awata, 2007; Jolivet et al., 2003], the most relevant calculation is not the response to a single earthquake but rather the response to a sequence of earthquakes that give rise to large fault offsets. Assuming a sequence of periodic earthquakes with recurrence interval $T$ and exploiting the fact that the Maxwell rheology is linear, we can sum the velocities from a single earthquake, $v_{1}$, to obtain the response from $N$ previous earthquakes, $v_{N}=\sum_{j=0}^{j=N} v_{1}(t+j T)$, where $t$ is the time since the most recent earthquake [Savage and Prescott, 1978; Savage, 2000; Hetland and Hager, 2005, 2006a]. As the number of earthquakes $N$ increases, interseismic velocity profiles approach a cycle invariant state (Figure 5) and in the limit that $N$ goes to infinity, the cycle invariant velocities, $v$, become,

$$
v=\Delta \mathrm{u}\left(C_{1} e^{-\beta_{1} t}+C_{2} e^{-\beta_{2} t}\right)
$$

where $\Delta u$ is the coseismic offset. The coefficients $\left(C_{1}, C_{2}\right)$ and relaxation times $\left(\beta_{1}, \beta_{2}\right)$ in equation (1) are complicated 
Table 1. Summary of Preseismic and Postseismic Geodetic Velocities and Inferred Viscosity Estimates for Both Two- and Three-Layer Models

\begin{tabular}{lcc}
\hline & $1997 M_{W}=7.6 \mathrm{Manyi}$ & $2001 L=7.8 \mathrm{Kokoxili}$ \\
\hline Preseismic $\Delta v(200 \mathrm{~km})$ & $3 \pm 1 \mathrm{~mm} / \mathrm{yr}^{\mathrm{a}}$ & - \\
Preseismic $\Delta v(600 \mathrm{~km})$ & - & $12 \pm 2 \mathrm{~mm} / \mathrm{yr}{ }^{\mathrm{b}}$ \\
Postseismic velocity & $75 \pm 19 \mathrm{~mm} / \mathrm{yr}^{\mathrm{c}}$ & $62 \pm 4 \mathrm{~mm} / \mathrm{yr}$ \\
2-Layer preseismic $\eta$ & $10^{19.1} \mathrm{~Pa} \cdot \mathrm{s}$ & $10^{18.6} \mathrm{~Pa} \cdot \mathrm{s}$ \\
2-Layer postseismic $\eta$ & $10^{18.4} \mathrm{~Pa} \cdot \mathrm{s}$ & $10^{20.9} \mathrm{~Pa} \cdot \mathrm{s}$ \\
2-Layer $|\Delta \log \eta|$ & $0.7 \pm 0.2$ & $1.5 \pm 0.5$ \\
3-Layer preseismic $\eta$ & $10^{17.7} \mathrm{~Pa} \cdot \mathrm{s}$ & $10^{18.2} \mathrm{~Pa} \cdot \mathrm{s}$ \\
3-Layer postseismic $\eta$ & $10^{18.0} \mathrm{~Pa} \cdot \mathrm{s}$ & $10^{18.8} \mathrm{~Pa} \cdot \mathrm{s}$ \\
3-Layer $|\Delta \log \eta|$ & $0.2 \pm 0.2$ & $0.5 \pm 0.3$ \\
\hline
\end{tabular}

The preseismic $\Delta v$ is the differential velocity over apertures of 200 and $600 \mathrm{~km}$ wide for the Manyi and Kokoxili cases respectively (Figure 3). For the three-layer case the midcrustal thickness is assumed to be $h=10 \mathrm{~km}$, with other layer thickness models in the Appendix.

${ }^{\mathrm{a}}$ Bell et al. [2011].

${ }^{\mathrm{b}}$ Zhang et al. [2004].

${ }^{\mathrm{c}}$ Ryder et al. [2007].

${ }^{\mathrm{d}}$ ChaoJun et al. [2009].

functions of midcrustal viscoelastic layer thickness, depth of the upper elastic layer, depth to which the coseismic rupture extends, Maxwell time, earthquake recurrence interval, and wave number (Appendix A). Matlab code implementing this solution is given in the supporting information. This spun-up three-layer solution shares the layer-like geometry of previous three-dimensional models of postseismic deformation [Ryder et al., 2007] and the dual relaxation times of the single earthquake solution [Segall, 2010], but differs in that in addition to predicting near-fault postseismic variations it also satisfies the far-field plate motion constraints (Figure 6a).

[14] The reason that the spun-up three-layer model satisfies the plate motion boundary condition at a distance closer to the fault trace than does the two-layer model (Figure 6b) is that coseismically generated elastic displacements in the lowest (mantle-like) layer are slowly restored to their initial positions. This elastic rebound of the mantle induces flow at the base of the viscoelastic layer in the direction opposite to the sense of coseismic slip. The reverse flow at the base of the viscoelastic layer in turn limits the magnitude and spatial extent of interseismic velocities in the midcrustal layer, with the largest effects near the fault trace where the coseismic stresses in the mantle layer are largest. As a result, for the same viscosity, the three-layer model velocity gradients are more localized across the fault than those of the two-layer model [Hearn, 2003].

[15] To illustrate the differences in behavior between the two- and three-layer models, we consider a simple synthetic example of a fault slipping at a rate $s_{0} \mathrm{~mm} / \mathrm{yr}$ with a recurrence interval of $T=300$ years. Fault-parallel velocity profiles for both the two- and three-layer models are calculated with a viscosity of $\eta=10^{19} \mathrm{~Pa} \cdot \mathrm{s}$ and a layer thickness of $h=20 \mathrm{~km}$ is assumed for the three-layer model (Figure 6). Both models produce rapid pulses of deformation immediately after an earthquake where the near-fault velocities may exceed the long-term differential velocity by a factor of five or more (Figures 6). The primary difference between the two- and three-layer models is that late in the earthquake cycle, the two-layer model has a differential velocity of $<0.6$ $s_{0} \mathrm{~mm} / \mathrm{yr}$ across a $600 \mathrm{~km}$ fault-perpendicular transect, while the three-layer model solution maintains a velocity gradient of $\sim 1 s_{0} \mathrm{~mm} / \mathrm{yr}$ across same transect, equivalent to the longterm fault slip rate, $s_{0}$ (Figure 6). The two-layer model with a small recurrence interval or large viscosity can maintain a comparable near-field velocity gradient across a $\sim 600 \mathrm{~km}$ fault-perpendicular transect, but at the cost of a much smaller magnitude $\left(<2 s_{0} \mathrm{~mm} / \mathrm{yr}\right)$ pulse of postseismic deformation [Savage and Prescott, 1978]. Additionally, postseismic deformation is more limited in spatial extent in the threelayer model (within $\sim 200 \mathrm{~km}$ of the fault trace) than in the two-layer model (Figure 6).
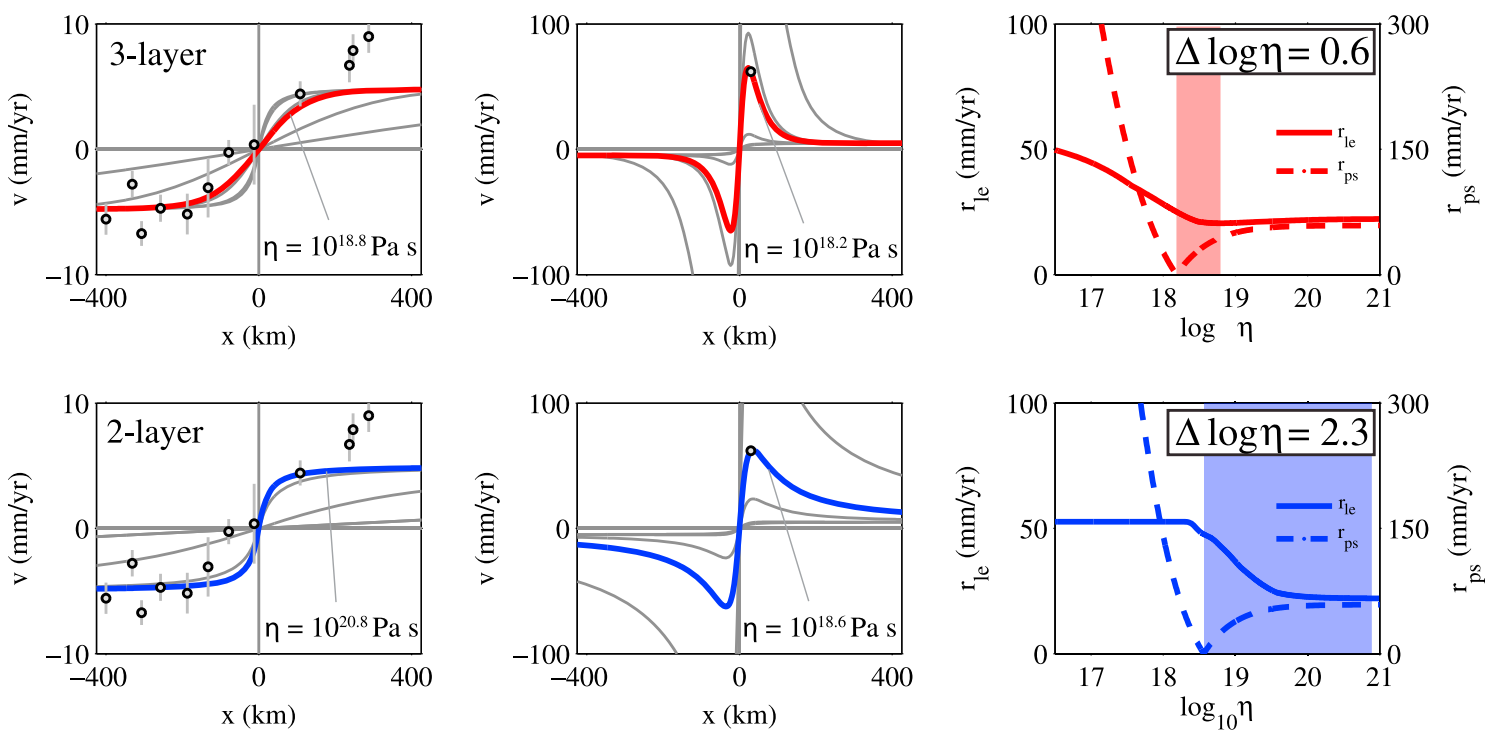

Figure 8. Same as Figure 7 but for the Kokoxili earthquake with preseismic and postseismic velocity estimates from Zhang et al. [2004] and ChaoJun et al. [2009], respectively. The minima of the preseismic and postseismic residuals are closer together for the three-layer model, $|\Delta \log \eta|=0.6$, than for the two-layer model, $|\Delta \log \eta|=2.3$. 

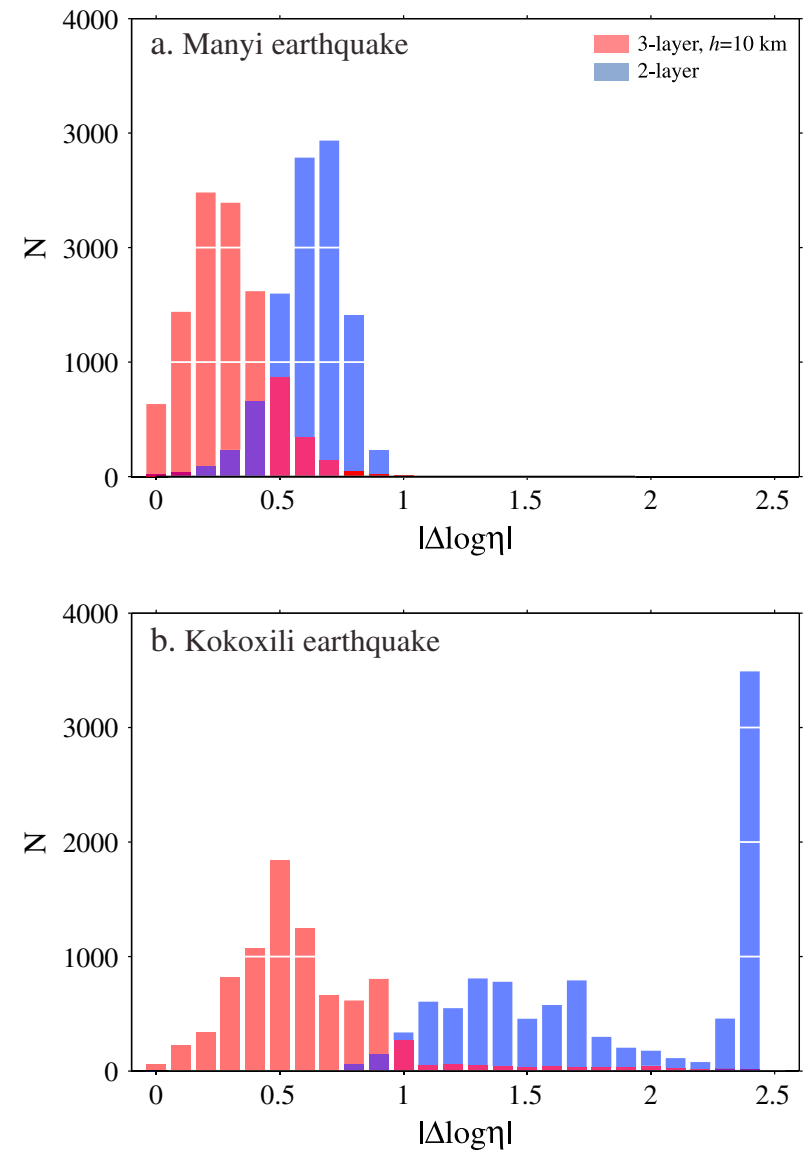

Figure 9. Repeatability of the differential viscosity estimates. Uncertainties in geodetic data are assumed to be normally distributed and 10,000 synthetic data sets are realized based on the $1 \sigma$ uncertainties in the data. The resultant histograms show variation in best-fitting preseismic and postseismic estimates of differential viscosity, $|\Delta \log \eta|$. Results for a three-layer model with midcrustal thicknesses of $h=10 \mathrm{~km}$ are shown in red $(|\Delta \log \eta|=0.2 \pm 0.2$ Manyi, $|\Delta \log \eta|=0.5 \pm 0.3$ Kokoxili) and in blue for the two-layer case $\quad(|\Delta \log \eta|=0.7 \pm 0.2 \quad$ Manyi, $\quad|\Delta \log \eta|=1.5 \pm 0.5$ Kokoxili). Differential viscosity estimates are generally repeatable for both the Manyi and Kokoxili earthquakes, though for both cases there are a small number of data noise realizations where $|\Delta \log \eta|$ is equivalent for both the two- and three-layer cases. For both models, a larger differential viscosity is required to explain the Kokoxili preseismic and postseismic velocities than for Manyi case.

\section{Inference of Midcrustal Viscosity in Tibet}

\subsection{The Manyi and Kokoxili Earthquakes}

[16] To determine which viscosities best-fit both the preseismic and postseismic velocities associated with the Manyi and Kokoxili earthquakes, we systematically compare the predictions from two- and three-layer models with viscosities ranging from $10^{16}$ to $10^{21} \mathrm{~Pa} \cdot \mathrm{s}$. For the three-layer models we also vary the thickness of the viscoelastic layer, $h$, between 1 and $20 \mathrm{~km}$ below a $20 \mathrm{~km}$ thick upper crust. In addition to the geodetic observables, these models require estimates of the earthquake recurrence interval, long-term fault slip rate, and effective fault locking depth. Geologic observations of long-term terraces and channel offsets have been used to suggest a recurrence interval of $300 \pm 50$ years for ruptures similar to the Kokoxili event [Haibling et al., 2005]. We also assume a slip rate on the Kunlun fault of $10 \mathrm{~mm} / \mathrm{yr}$, consistent with Pleistocene slip rates on the central and western Kunlun fault of $\sim 11 \pm 2 \mathrm{~mm} / \mathrm{yr}$ [Van der Woerd et al., 1998, 2000, 2002] and 6.5-8.7 $\pm 1.8 \mathrm{~mm} / \mathrm{yr}$ [Cowgill et al., 2009]. We take $s_{0}=10 \mathrm{~mm} / \mathrm{yr}$ as a representative fault slip rate and $T=300$ years as the average earthquake recurrence interval. We assume that the slip rate and recurrence interval on the Manyi fault splay are identical to those along the central Kunlun fault $\left(\sim 94^{\circ} \mathrm{E}\right)$ as we are unaware of any currently published local constraints on these parameters. Furthermore, we assume an effective locking depth of $D=20 \mathrm{~km}$, consistent with estimates of coseismic slip during the earthquakes [e.g., Antolik et al., 2004; Lasserre et al., 2005; Funning et al., 2007] and the fact that most major earthquakes rupture the entire upper crust.

[17] For the three-layer model with a $10 \mathrm{~km}$ thick midcrustal layer, the preseismic and postseismic data from the Manyi earthquake are best explained by a viscosity of $\sim 10^{17.8} \mathrm{~Pa} \cdot \mathrm{s}$. (Figure 7, supporting information). The minimum postseismic residual is $<1 \mathrm{~mm} / \mathrm{yr}$ with viscosity $\eta=10^{18.0} \mathrm{~Pa} \cdot \mathrm{s}$ and the minimum preseismic sum of residuals is $12 \mathrm{~mm} / \mathrm{yr}$ with viscosity $\eta=10^{17.7} \mathrm{~Pa} \cdot \mathrm{s}$. The goodness-of-fit decreases markedly for models using the same layer thickness $(h=10 \mathrm{~km})$ but a viscosity of $\eta=10^{21.0} \mathrm{~Pa} \cdot \mathrm{s}$, where the residuals increase to $\sim 63 \mathrm{~mm} / \mathrm{yr}$ (preseismic) and $\sim 72 \mathrm{~mm} / \mathrm{yr}$ (postseismic). In contrast, the two-layer model requires a viscosity of $10^{18.4} \mathrm{~Pa} \cdot \mathrm{s}$ to explain the Manyi earthquake postseismic data equally well (minimum postseismic residual of $<1 \mathrm{~mm} / \mathrm{yr}$ ), and a significantly higher viscosity, $10^{19.1} \mathrm{~Pa} \cdot \mathrm{s}$, to explain the preseismic data (minimum preseismic sum of residuals of $12 \mathrm{~mm} / \mathrm{yr}$; Figure 7 and Table 1). The difference between the best-fit viscosity for the preseismic velocities and the best-fit viscosity for the postseismic velocities can be described by the quantity $|\Delta \log \eta|$, with a minimum at zero. For the $h=10 \mathrm{~km}$ thick three-layer model, $|\Delta \log \eta|=0.3$, indicating that the best-fit viscosities for both the preseismic and postseismic GPS data differ by only $\sim 20 \%$ while for the two-layer model the bestfitting viscosities differ by $>50 \%,|\Delta \log \eta|=0.7$.

[18] For the Kokoxili earthquake, $500 \mathrm{~km}$ to the east of the Manyi epicenter, the three-layer model with $h=10 \mathrm{~km}$ fits the preseismic and postseismic data best with $10^{18.8} \mathrm{~Pa} \cdot \mathrm{s}$ (minimum preseismic sum of residuals of $20 \mathrm{~mm} / \mathrm{yr}$ ) and $10^{18.2} \mathrm{~Pa} \cdot \mathrm{s}$ (minimum postseismic residual of $<1 \mathrm{~mm} / \mathrm{yr}$ ), respectively (Figure 8, supporting information). In contrast to the three-layer model, the two-layer model requires a viscosity of $10^{18.6} \mathrm{~Pa} \cdot \mathrm{s}$ to explain the postseismic data equally well (minimum postseismic residual of $<1 \mathrm{~mm} / \mathrm{yr}$ ), and a viscosity two orders of magnitude larger $\left(10^{20.9} \mathrm{~Pa} \cdot \mathrm{s}\right)$ to explain the preseismic velocities (Figure 8). Similar to the differential viscosities estimated from the preseismic and postseismic Manyi observations, we find $|\Delta \log \eta|=0.6$ for the three-layer model while $|\Delta \log \eta|=2.3$ for the two-layer model.

\subsection{Sensitivity to Observational Uncertainties and Parameter Trade-Offs}

[19] To assess the sensitivity of two- and three-layer viscosity estimates to uncertainties in the geodetic observables, we 


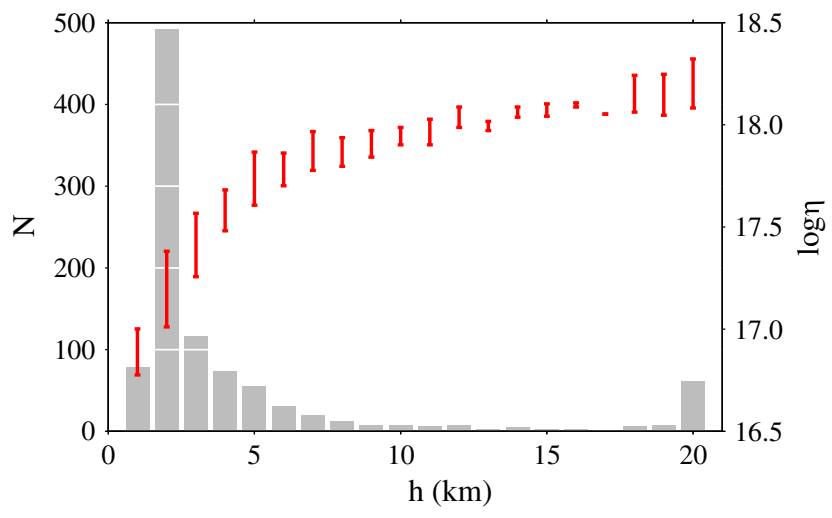

Figure 10. Nonuniqueness of parameter estimates inferred from model postseismic GPS time series. Assuming that the data are normally distributed, we generated 1000 synthetic data sets based on the $1 \sigma$ uncertainties in the data. The best-fitting parameter pairs (channel thickness $h,|\Delta \log \eta|$ ) are mapped for each simulation run in red. Underneath, a histogram of the numbers of simulation runs that resulted in each best-fitting channel thickness is shown in grey. In most (49\%) of the simulations, a thin channel $(\sim 2 \mathrm{~km})$ fits the data best, but this result is not unique. Models with thicker channels also explain the data in a significant number of simulations (51\%).

analyze simulations based on synthetic realizations of data noise. Assuming that the geodetic data uncertainties are normally distributed, we generated 10,000 synthetic velocity data sets and solved for the best-fitting viscosities for each of these realizations. The calculated frequency distributions indicate that the Manyi earthquake differential viscosity estimates may overlap, with $|\Delta \log \eta|=0.2 \pm 0.2$ for the three-layer case and $|\Delta \log \eta|=0.7 \pm 0.2$ for the two-layer case (Figure 9a). The differential viscosity estimates from the preseismic and postseismic data from the Kokoxili earthquake are perhaps more robust, with $|\Delta \log \eta|=0.5 \pm 0.3$ for the three-layer case and $|\Delta \log \eta|=1.5 \pm 0.5$ for the two-layer case with maximum variations between 50 and $200 \%$ of the mean value (Figure 9b). These variations suggest that the distinction between preseismic and postseismic viscosities in the twoand three-layer models is not likely to result from observational errors alone.

[20] Thus far, our estimates of postseismic viscosity have been based on average velocities over the first one (333 days for the Kokoxili event [ChaoJun et al., 2009]) or two (730 days for the Manyi event [Ryder et al., 2007]) years of the earthquake cycle. However, isolated continuous GPS time series following the Kokoxili rupture (Figure 1) may be tested against predictions from the three-layer earthquake cycle models [ChaoJun et al., 2009]. Using data from GPS station BDGD (Figure 4), $30 \mathrm{~km}$ south of the fault trace, we systematically test midcrustal thicknesses $(h=1-20 \mathrm{~km})$ and viscosities $\left(\eta=10^{16-21} \mathrm{~Pa} \cdot \mathrm{s}\right)$ to find the parameters that best-fit the time series (Figures 4 and 10). Models with a very thin and low viscosity ( $\left.h=2 \mathrm{~km}, \eta=10^{17.25} \mathrm{~Pa} \cdot \mathrm{s}\right)$ viscoelastic layer at the base of the upper crust reproduce the time series the most accurately (mean residual displacement magnitude of $3 \mathrm{~mm}$; Figure 4). Repeated simulations based on synthetic noise realizations suggest that these parameter estimates are not uniquely determined. Best-fit viscoelastic layer thicknesses, $h$, and viscosities, $\eta$, estimated from 1000 synthetic realizations of data noise based on the reported $1 \sigma$ position uncertainties $(15 \mathrm{~mm})$ [ChaoJun et al., 2009] reveal cases where higher-viscosity $\left(\sim 10^{18} \mathrm{~Pa} \cdot \mathrm{s}\right)$ thick $(h \sim 15-20 \mathrm{~km})$ layers can explain the data as well as than low-viscosity $\left(10^{16.5} \mathrm{~Pa} \cdot \mathrm{s}\right)$ thin layer $(h \sim 1-5 \mathrm{~km})$ cases (Figure 10). Thus, although the inference of a weak midcrustal $\left(\eta<10^{18.5} \mathrm{~Pa} \cdot \mathrm{s}\right)$ layer beneath the upper crust of the Tibetan plateau is consistent with the average preseismic and postseismic velocities, further constraints on the thickness and viscosity of the midcrust underneath Tibet will require postseismic time series with smaller uncertainties and other supporting constraints such as seismic estimates of layer thickness. A similar tradeoff between channel thickness and viscosity exists in Poisseuille flow models designed to explain topographic gradients at the margins of the Tibetan plateau [e.g., Clark and Royden, 2000].

\section{Discussion}

[21] The two-layer Maxwell viscoelastic earthquake cycle model [e.g., Savage and Prescott, 1978] has been used extensively to estimate fault slip rates based on interseismic velocities in California [Savage, 1990; Segall, 2002; Dixon et al., 2002, 2003], Tibet [Hilley et al., 2005], and Turkey [Ergintav et al., 2002; Motagh et al., 2007]. However, due to the fact that recurrence intervals for large earthquakes may reach hundreds of years and that high-precision spacebased geodetic observations have decadal durations, these observations provide only a snapshot of deformation throughout the seismic cycle. Information about the maximal variations in earthquake cycle activity may be inferred from the differences between preseismic and postseismic deformation. Unfortunately, few large $\left(M_{W}>7.5\right)$ strike-slip earthquakes have occurred with high-precision geodetic observations of both preseismic and postseismic velocities. In addition to $1997 M_{W}=7.6$ Manyi and $2001 M_{W}=7.8$ Kokoxili earthquakes in Tibet, the $1999 M_{W}=7.6$ Izmit earthquake meets this criteria [Ergintav et al., 2009]. Before the Izmit event ruptured the westernmost North Anatolian fault zone, GPS observations indicate a localized velocity gradient of $\sim 25 \mathrm{~mm} / \mathrm{yr}$ within $\sim 200 \mathrm{~km}$ of the fault trace [Ergintav et al., 2002; Bürgmann et al., 2002]. In the years following the coseismic rupture, rapid postseismic deformation occurred $(>60 \mathrm{~mm} / \mathrm{yr})$, but within a decade, postseismic velocities had decayed to within $15 \%$ of preseismic magnitudes [Ergintav et al., 2009]. Assuming a two-layer model of the Earth with an elastic upper crust and a Maxwell viscoelastic upper mantle, the effective viscosity of the lower layer would have to increase by a factor of 10 several months after the earthquake to explain the time evolution of the postseismic velocities [Hearn et al., 2009]. Similar to the geodetic observations from across the Manyi and Kunlun rupture zones, these North Anatolian fault zone observations [Ergintav et al., 2009] suggest that a two-layer Maxwell viscoelastic earthquake cycle model alone may not adequately explain both preseismic and postseismic velocities following large earthquakes [Hetland and Hager, 2006a]. However, caution must be exercised when directly comparing the viscosity estimates inferred from three-dimensional models to the viscosity estimates reported here for two reasons: our model does not incorporate 
three-dimensional effects, and published three-dimensional models do not incorporate spin-up effects, limiting their application to only postseismic deformation.

[22] In addition, other rheologies (e.g., Burgers, standard linear solid, nonlinear), depth-varying Maxwell viscosities, and afterslip have been suggested as alternative candidates to explain similar behavior across the earthquake cycle [e.g., Hetland and Hager, 2005, 2006a, 2006b; Ryder et al., 2007; Pollitz, 2005; Hearn et al., 2009; Ryder et al., 2011; Yamasaki and Houseman, 2012]. More complicated rheologies may also be required in Tibet as we find that $\sim 50 \%$ higher viscosities are required to explain the geodetic data prior to and following the Kokoxili earthquake than for the Manyi earthquake in both two- and three-layer models (Figure 9, Appendix A).

\section{Conclusions}

[23] Using time-dependent earthquake cycle models, geodetic data near active faults can be used to constrain crustal and upper mantle rheology. Although few geodetic observations of deformation throughout an entire earthquake cycle exist (e.g., Parkfield), both the beginning and end of the earthquake cycle have been observed in Tibet and show both somewhat localized velocity gradients late in the earthquake cycle and rapid postseismic deformation immediately following coseismic ruptures [e.g., Ryder et al., 2007, 2011]. These observations are not consistent with the predictions of the single Maxwell viscosity two-layer earthquake cycle model that can effectively explain either localized preseismic deformation or rapid postseismic velocities [e.g., Savage and Prescott, 1978]. In contrast, the spun-up three-layer earthquake cycle model developed here may provide a more unified representation of earthquake cycle phenomenology than the two-layer model solution. In addition to predicting rapid postseismic deformation within $\sim 50 \mathrm{~km}$ of the fault trace, the three-layer model predicts localized pre-earthquake strain satisfying far-field kinematic boundary conditions (i.e., plate motion constraints) within 20 locking depths of the fault trace. This distance is greater than predicted by steady elastic half-space models [Savage and Burford, 1973] but less than two-layer viscoelastic models [Savage and Prescott, 1978]. Applied to preseismic and postseismic geodetic observations in Tibet, the three-layer model with a relatively weak $\left(\eta=10^{16.5-18.5} \mathrm{~Pa} \cdot \mathrm{s}\right)$ midcrustal layer can explain geodetic observations before and after the 1997 $M_{W}=7.6$ Manyi and $2001 M_{W}=7.8$ Kokoxili earthquakes. Our estimate of a midcrustal viscosity of $\eta=10^{16.5-18.8} \mathrm{~Pa} \cdot \mathrm{s}$ is 1-3 orders of magnitude lower than that inferred from a two-layer Earth model constrained by preseismic observations alone [Hilley et al., 2005]. Within the context of channel flow models for the evolution of the Tibetan plateau [Bird, 1991; Royden, 1996; Royden et al., 1997; Clark and Royden, 2000; Shen et al., 2001; Beaumont et al., 2001, 2004; Jamieson et al., 2004, Clark et al., 2005; Cook and Royden, 2008] and contemporary seismic inferences of midcrustal structure [Nelson et al., 1996; Makovsky et al., 1996] the three-layer model developed here is consistent with the idea of a relatively weak midcrustal layer only if it located at the base of the upper crust.

\section{Appendix A: Complete Three-Layer Model Solution for an Infinite Sequence of Earthquakes}

[24] The velocity solution is,

$$
v=\Delta u\left(C_{1} e^{-\beta_{1} t}+C_{2} e^{-\beta_{2} t}\right)
$$

where the coefficients $\left(C_{1}, C_{2}\right)$ and relaxation times $\left(\beta_{1}, \beta_{2}\right)$ are complicated functions of the midcrustal viscoelastic layer thickness $h$, the depth of the upper elastic layer $H$, the depth to which the coseismic rupture extends $D$, the earthquake recurrence interval $T$, the wave number $k$, the slip on the fault during the earthquake $\Delta u$, and the reciprocal of the Maxwell time $\beta=\mu / 2 \eta$, where $\mu$ is shear modulus and $\eta$ is viscosity,

$$
\begin{gathered}
C_{1}=-2 i k \beta \kappa_{1} \kappa_{2}\left(\kappa_{3}-\kappa_{4}\right) /\left(\kappa_{9} \kappa_{8}|k|^{2}\right)\left(\kappa_{9}+\kappa_{10}\right)\left(\frac{e^{-\beta T \kappa_{11}}}{e^{-\beta T \kappa_{11}}-1}\right) \\
C_{2}=-2 i k \beta \kappa_{1} \kappa_{2}\left(\kappa_{3}-\kappa_{4}\right) /\left(\kappa_{9} \kappa_{8}|k|^{2}\right)\left(\kappa_{9}-\kappa_{10}\right)\left(\frac{e^{\beta T \kappa_{12}}}{e^{\beta T \kappa_{12}}-1}\right) \\
\beta_{1}=-\beta \kappa_{11} \\
\beta_{2}=\beta \kappa_{12}
\end{gathered}
$$

where the geometric constants $\kappa_{i}$ are,

$$
\begin{gathered}
\kappa_{1}=\sinh (h|k|) \\
\kappa_{2}=\sinh (D|k|) \\
\kappa_{3}=\cosh (H|k|) \\
\kappa_{4}=\sinh (H|k|) \\
\kappa_{5}=\cosh (h|k|) \\
\kappa_{6}=2\left(\kappa_{3} \kappa_{5}+\kappa_{4} \kappa_{5}+2 \kappa_{1} \kappa_{4}\right) \\
\kappa_{7}=2\left(\kappa_{3} \kappa_{5}+\kappa_{1} \kappa_{3}+\kappa_{4} \kappa_{5}+\kappa_{1} \kappa_{4}\right) \\
\kappa_{8}=\left(\kappa_{1}+\kappa_{5}\right)\left(\kappa_{3}+\kappa_{4}\right) \\
\kappa_{9}=\sqrt{-4 \kappa_{1}^{2} \kappa_{3} \kappa_{4}+\kappa_{3}^{2} \kappa_{5}^{2}+2 \kappa_{3} \kappa_{4} \kappa_{5}^{2}+\kappa_{4}^{2} \kappa_{5}^{2}} \\
\kappa_{10}=\kappa_{1} \kappa_{3}-\kappa_{1} \kappa_{4} \\
\kappa_{11}=\kappa_{9} / \kappa_{8}-\kappa_{6} / \kappa_{7} \\
\kappa_{12}=\kappa_{9} / \kappa_{8}+\kappa_{6} / \kappa_{7}
\end{gathered}
$$

[25] Acknowledgments. This research was supported by the Department of Energy Computational Science Graduate Fellowship under grant number DE-FG02-97ER25308 and Harvard University. Tom Parsons, Leigh Royden, one anonymous associate editor, and one anonymous reviewer provided thoughtful comments and suggestions.

\section{References}

Antolik, M., R. E. Abercrombie, and G. Ekstrom (2004), The 14 November 2001 Kokoxili (Kunlunshan), Tibet earthquake: Rupture transfer through a large extensional step-over, Bull. Seis. Soc. Am., 94(4), 1173-1194.

Beaumont, C., R. A. Jamieson, M. H. Nguyen, and B. Lee (2001), Himalayan tectonics explained by extrusion of a low-viscosity channel coupled to focused surface denudation, Nature, 414, 738-742.

Beaumont, C., R. A. Jamieson, M. H. Nguyen, and S. Medvedev (2004), Crustal channel flows: 1. Numerical models with applications to the tectonics of the Himalayan-Tibetan orogeny, J. Geophys. Res., 109 B06406, doi:10.1029/2003JB002809. 


\section{DEVRIES AND MEADE: EARTHQUAKE CYCLE WITH A WEAK LAYER}

Bell, M. A., J. R. Elliott, and B. E. Parsons (2011), Interseismic strain accumulation across the Manyi (Tibet) prior to the $1997 \mathrm{M}_{\mathrm{W}} 7.6$ earthquake, Geophys. Res. Lett., 38, L24302, doi:10.1029/2011GL049762.

Bilham, R., K. Larson, J. Freymueller, and Project Idylhim members (1997), GPS measurements of present-day convergence across the Nepa Himalaya, Nature, 386(6), 61-64.

Bird, P. (1991), Lateral extrusion of lower crust from under high topography, in the isostatic limit, J. Geophys. Res., 96(B6), 10275-10286.

Burchfiel, B. C., L. H. Royden, R. D. van der Hilst, and B. H. Hager (2008), A geological and geophysical context for the Wenchuan earthquake of 12 May 2008, Sichuan, People's Republic of China, GSA Today, 18(7), 4-11.

Bürgmann, R., S. Ergintav, P. Segall, E. H. Hearn, S. McClusky, R. E. Reilinger, H. Woith, and J. Zschau (2002), Time-dependent distributed afterslip on and Deep below the Izmit Earthquake rupture, Bull. Seis. Soc. Am., 92(1), 126-137.

ChaoJun, Z., C. JianLing, and S. YaoLin (2009), Studying the viscosity of lower crust of Qinghai-Tibet Plateau according to post-seismic deformation, Sci. China Ser. D, 5(3), 411-419.

Chen, Q., J. Freymueller, Q. Wang, Z. Yang, C. Xu, and J. Liu (2004), A deforming block model for the present day tectonics of Tibet, J. Geophys. Res., 109, B01403, doi:10.1029/2002JB002151.

Clark, M. K., and L. H. Royden (2000), Topographic ooze: Building the eastern margin of Tibet by lower crustal flow, Geology, 28(8), 703-706.

Clark, M. K., J. W. M. Bush, and L. H. Royden (2005), Dynamic topography produced by lower crustal flow against rheological strength heterogeneities bordering the Tibetan Plateau, Geophys. J. Int., 162, 575-590.

Cook, K., and L. H. Royden (2008), The role of crustal strength variations in shaping orogenic plateaus, with application to Tibet, J. Geophys. Res., 113, B08407, doi:10.1029/2007JB005457.

Cowgill, E., R. D. Gold, C. Xuanhua, W. Xiao-Feng, J. R. Arrowsmith, and J. Southon (2009), Low quaternary slip rate reconciles geodetic and geologic rates along the Altyn Tagh fault, northwestern Tibet, Geology, $37(7), 647-650$

Diao, F., X. Xiong, and R. Wang (2011), Mechanisms of transient deformation following the $2001 \mathrm{M}_{\mathrm{W}} 7.8 \mathrm{Kunlun}$ (China) Earthquake, Pure Appl. Geophys., 168, 767-779.

Dixon, T. H., J. Decaix, F. Farina, K. Furlong, R. Malservisi, R. Bennett, R. Suarez-Vidal, J. Fletcher, and J. Lee (2002), Seismic cycle and rheological effects on estimation of present-day slip rates for the Agua Blanca and San Miguel-Vallecitos faults, northern Baja California, Mexico, J. Geophys. Res., 107(B10), 2226, doi:10.1029/2000JB000099.

Dixon, T. H., E. Norabuena, and L. Hotaling (2003), Paleoseismology and global positioning system: earthquake-cycle effects and geodetic versus geologic fault slip rates in the eastern California shear zone, Geology, 31(1), 55-58.

Ergintav, S., R. Bürgmann, S. McClusky, R. Cakmak, R. E. Reilinger, O. Lenk, A. Barka, and H. Ozener (2002), Postseismic deformation near the Izmit earthquake (17 August 1999, M=7.5) rupture zone, Bull. Seis. Soc. Am., 92(1), 194-207.

Ergintav, S., S. McClusky, E. Hearn, R. Reilinger, R. Cakmak, T. Herring, H. Ozener, O. Lenk, and E. Tari (2009), Seven years of postseismic deformation following the $1999, \mathrm{M}=7.4$ and $\mathrm{M}=7.2$, Izmit-Duzce, Turkey earthquake sequence, J. Geophys. Res., 114, B07403, doi:10.1029/ 2008JB006021.

Flesch, L. M., W. E. Holt, P. G. Silver, M. Stephenson, C. Wang, and W. Chan (2005), Constraining the extent of crust-mantle coupling in central Asia using GPS, geologic and shear save splitting data, Earth Planet. Sci. Lett., 238, 248-268.

$\mathrm{Fu}, \mathrm{B}$., and Y. Awata (2007), Displacement and timing of left-lateral faulting in the Kunlun Fault Zone, northern Tibet, inferred from geologic and geomorphic features, J. Asian Sciences, 29(2-3), 253-265.

Funning, G. J., B. Parsons, and T. J. Wright (2007), Fault slip in the 1997 Manyi, Tibet earthquake from linear elastic modeling of InSAR displacements, Geophys. J. Int., 169, 988-1008.

Gilbert, F., and G. E. Backus (1966), Propagator matrices in elastic wave and vibration problems, Geophysics, 31, 326-332.

Grujic, D., M. Casey, C. Davis, L. Hollister, R. Kündig, T. Pavlis, and S. Schmid (1996), Ductile extrusion of the Higher Himalayan Crystalline in Bhutan: evidence from quartz microfabrics, Tectonophysics, 260, 21-43.

Grujic, D., L. Hollister, and R. Parrish (2002), Himalayan metamorphic sequence as an orogenic channel: insight from Bhutan, Earth Planet. Sci. Lett., 198, 177-191.

Haibing, L., J. Van der Woerd, P. Tapponnier, Y. Klinger, Q. Xuexiang, Y. Jingsui, and Z. Yintang (2005), Slip rate on the Kunlun fault at the Hongshiu Gou, and recurrence time of great events comparable to the 14/11/2001, $\mathrm{M}_{\mathrm{W}}=7.9$ Kokoxili earthquake, Earth Planet. Sci. Lett., 237 , 285-299.
Hearn, E. H. (2003), What can GPS data tell us about the dynamics of postseismic deformation?, Geophys. J. Int., 155, 753-777.

Hearn, E. H., S. McClusky, S. Ergintav, and R. E. Reilinger (2009), Izmit earthquake postseismic deformation and dynamics of the North Anatolian Fault Zone, J. Geophys. Res., 114, B08405, doi:10.1029/ 2008JB006026.

Hetland, E., and B. H. Hager (2005), Postseismic and interseismic displacements near a strike-slip fault: A two-dimensional theory for general linear viscoelastic rheologies, J. Geophys. Res., 110, B10401, doi:10.1029/ 2005JB003689.

Hetland, E., and B. H. Hager (2006a), The effects of rheological layering on post-seismic deformation, Geophys. J. Int., 166, 277-292.

Hetland, E., and B. H. Hager (2006b), Interseismic strain accumulation: spin-up, cycle invariance, and irregular rupture sequences, Geochem Geophys. Geosyst., 7, Q05004, doi:10.1029/2005GC001087.

Hilley, G. E., R. Bürgmann, P. Zhang, and P. Molnar (2005), Bayesian inference of plastosphere viscosities near the Kunlun Fault, northern Tibet, Geophys. Res. Lett., 32, L01302, doi:10.1029/2004GL021658.

Hilley, G. E., K. M. Johnson, M. Wang, Z.-K. Shen, and R. Bürgmann (2009), Earthquake-cycle deformation and fault slip rates in northern Tibet, Geology, 37(1), 31-34

Holt, W. E. (2000), Correlated crust and mantle strain fields in Tibet, Geology, 28(1), 67-70.

Jackson, J. (2002), Strength of the continental lithosphere: time to abandon the jelly sandwich?, GSA Today, 12(9), 4-9.

Jackson, J., D. McKenzie, K. Priestley, and B. Emmerson (2008), New views on the structure and rheology of the lithosphere, J. Geol. Soc., 165, 453-465.

Jamieson, R. A., C. Beaumont, S. Medvedev, and M. H. Nguyen (2004), Crustal channel flows: 2. Numerical models with implications for metamorphism in the Himalayan-Tibetan orogen, J. Geophys. Res., 109, B06407, doi:10.1029/2003JB002811.

Jolivet, M., M. Brunel, D. Seward, Z. Xu, J. Yang, J. Malavieille, F. Roger, A. Leyreloup, N. Arnaud, and C. Wu (2003), Neogene extension and volcanism in the Kunlun Fault Zone, northern Tibet: New constraints on the age of the Kunlun Fault, Tectonics, 22(5), 1052, doi:10.1029/ 2002TC001428.

Lasserre, C., G. Peltzer, R. Crampé, Y. Klinger, J. Van der Woerd, and P. Tapponnier (2005), Coseismic deformation of the $2001 \mathrm{M}_{\mathrm{W}}=7.8$ Kokoxili earthquake in Tibet, measured by synthetic aperture radar interferometry, J. Geophys. Res., 110, B12408, doi:10.1029/2004JB003500.

Loveless, J. P., and B. J. Meade (2011), Partitioning of localized and diffuse deformation in the Tibetan Plateau from joint inversions of geologic and geodetic observations, Earth. Plan. Sci. Lett., 303, 11-24.

Makovsky, Y., S. L. Klemperer, L. Ratschbacher, L. D. Brown, M. Ling, W. Zhao, and F. Meng (1996), INDEPTH Wide-Angle reflection observation of P-wave-to-S-wave conversion from crustal bright spots in Tibet, Science, 274(5293), 1690-1691.

Matsu'ura, M., T. Tanimoto, and T. Iwasaki (1981), Quasi-static displacements due to faulting in a layered half-space with an intervenient viscoelastic layer, J. Phys. Earth, 29, 23-54.

Meade, B. J. (2007), Present-day kinematics at the India-Asia collision zone, Geology, 35(1), 81-84

Montesi, L. G. (2004), Controls of shear zone rheology and tectonic loading on postseismic creep, J. Geophys. Res., 109, B10404, doi:10.1029/ 2003JB002925.

Motagh, M., J. Hoffman, B. Kampes, M. Baes, and J. Zschau (2007), Strain accumulation across the Gazikoy-Saros segment of the North Anatolian Fault inferred from persistent scatterer interferometry and GPS measurements, Earth Planet. Sci. Lett., 255, 432-444

Nelson, K. D. et al. (1996), Partially molten middle crust beneath southern Tibet: Synthesis of Project INDEPTH results, Science, 274(5293), 1684-1688.

Nur, A., and G. Mavko (1974), Postseismic viscoelastic rebound, Science, 183(4121), 204-206.

Pollitz, F. (2005), Transient rheology of the upper mantle beneath central Alaska inferred from the crustal velocity field following the 2002 Denali earthquake, J. Geophys. Res., 110, B08407, doi:10.1029/2005JB003672.

Royden, L. H. (1996), Coupling and decoupling of crust and mantle in convergent orogens: Implications for strain partitioning in the crust, J. Geophys. Res., 101(B8), 17679-17705.

Royden, L. H., B. C. Burchfiel, R. W. King, E. Wang, Z. Chen, F. Shen, and Y. Liu (1997), Surface deformation and lower crustal flow in eastern Tibet Science, 276, 788-791.

Royden, L. H., B. C. Burchfiel, and R. D. van der Hilst (2008), The Geological Evolution of the Tibetan Plateau, Science, 321, 1054-1058.

Ryder, I., B. Parsons, T. J. Wright, and G. J. Funning (2007), Post-seismic motion following the 1997 Manyi (Tibet) earthquake: InSAR observations and modeling, Geophys. J. Int., 169(3), 1009-1027.

Ryder, I., R. Bürgmann, and F. Pollitz (2011), Lower crustal relaxation beneath the Tibetan Plateau and Qaidam Basin following the 2001 Kokoxili earthquake, Geophys. J. Int., 187, 613-630. 


\section{DEVRIES AND MEADE: EARTHQUAKE CYCLE WITH A WEAK LAYER}

Savage, J. C. (1990), Equivalent strike-slip earthquake cycles in half-space and lithosphere-asthenosphere earth models, J. Geophys. Res., 95(B4), 4873-4879.

Savage, J. C. (2000), Viscoelastic-coupling model for the earthquake cycle driven from below, J. Geophys. Res., 105(B11), 25525-25532.

Savage, J. C., and R. O. Burford (1973), Geodetic determination of relative plate motion in central California, J. Geophys. Res., 78(5), 832-845.

Savage, J. C., and W. H. Prescott (1978), Asthenosphere Readjustment and the Earthquake cycle, J. Geophys. Res., 83(B7), 3369-3376.

Segall, P. (2002), Integrating geologic and geodetic estimates of slip rate on the San Andreas fault system, Int. Geol. Rev., 44(1), 62-82.

Segall, P. (2010), Earthquake and Volcano deformation, 432 pp., Princeton University Press, Princeton, N. J.

Shen, F., L. H. Royden, and B. C. Burchfiel (2001), Large-scale crustal deformation of the Tibetan Plateau, J. Geophys. Res., 106(B4), 6793-6816.

Van der Woerd, J., F. J. Ryserson, P. Tapponnier, Y. Gaudemer, R. Finkel, A. S. Meriaux, M. Caffee, G. Zhao, and H. Qinlin (1998), Holocene leftslip rate determined by cosmogenic surface dating on the Xidatan segment of the Kunlun fault (Qinghai, China), Geology, 26(8), 695-698.

Van der Woerd, J., F. J. Ryserson, P. Tapponnier, A. S. Meriaux, Y. Gaudemer, B. Meyer, R. C. Finkel, M. W. Caffee, and G. Zhao (2000), Uniform slip rate along the Kunlun fault: Implications for seismic behavior and large-scale tectonics, Geophys. Res. Lett., 27(16), 2353-2356.
Van der Woerd, J., P. Tapponnier, F. J. Ryerson, A. S. Meriaux, B. Meyer, Y. Gaudemer, R. C. Finkel, M. W. Caffee, Z. Guoguang, and X. Zhiqin (2002), Uniform postglacial slip-rate along the central $600 \mathrm{~km}$ of the Kunlun fault (Tibet), from 26Al, 10Be, 14C dating of riser offsets, and climatic origin of the regional morphology, Geophys. J. Int., $148,356-388$.

Wallace, K., G. Yin, and R. Bilham (2004), Inescapable slow slip on the Altyn Tagh fault, Geophys. Res. Lett., 31, L09613, doi:10.1029/ 2004GL019724.

Ward, S. N. (1985), Quasi-static propagator matrices: creep on strike-slip faults, Tectonophysics, 120, 83-106.

Yamasaki, T., and G. A. Houseman (2012), The crustal viscosity gradient measured from post-seismic deformation: A case study of the 1997 Manyi (Tibet) earthquake, Earth Planet. Sci. Lett., 351-352, 104-114.

Yao, H., R. D. van der Hilst, and M. V. de Hoop (2006), Surface-wave array tomography in SE Tibet from ambient seismic noise and two-station analysis - I. Phase velocity maps, Geophys. J. Int., 166, 732-744.

Yao, H., C. Beghein, and R. D. van der Hilst (2008), Surface wave array tomography in SE Tibet from ambient seismic nosie and two-station analysis - II, Crustal and upper-mantle structure, Geophys. J. Int., 173, 205-219.

Zhang, P. et al. (2004), Continuous deformation of the Tibetan Plateau from global positioning system data, Geology, 32(9), 809-812. 